\title{
The prM-independent packaging of pseudotyped Japanese
} encephalitis virus

\author{
Hee Jung Lee ${ }^{1}$, Kyung-Il Min², Jungeun Lee ${ }^{1}$, Sin-Hyung Kang1, \\ Wonkyung Jeon ${ }^{3}$, Jae Hwan $\mathrm{Nam}^{4}$, Young Ran Ju${ }^{5}$ and Young Bong Kim*1
}

\begin{abstract}
Address: ${ }^{1}$ Department of Animal Biotechnology, College of Animal Bioscience \& Technology, Konkuk University, 1 Hwayang-dong, Gwangjin-gu, Seoul 143-701, Republic of Korea, 2Virus Vaccines Division, Korea Food \& Drug Administration, 194 Tongilro, Eunpyeong-gu, Seoul 122-704, Republic of Korea, ${ }^{3}$ Center for Herbal Medicine Improvement Research, Korea Institute of Oriental Medicine, 483 Expo-ro, Yuseong-gu, Daejeon 305-811, Republic of Korea, ${ }^{4}$ Department of Biotechnology, The Catholic University of Korea, 43-1 Yeokgok 2-dong, Wonmi-gu, Bucheon, Gyeonggi-do 420-743, Republic of Korea and ${ }^{5}$ Division of Arboviruses, Center for Immunology \& Pathology, National Institute of Health, Korea Centers for Disease Control and Prevention, 194 Tongilro, Eunpyeong-gu, Seoul 122-701, Republic of Korea
\end{abstract}

Email: Hee Jung Lee - ziniga@naver.com; Kyung-Il Min - onestar@kfda.go.kr; Jungeun Lee - eurofa@konkuk.ac.kr; SinHyung Kang - easternblot@naver.com; Wonkyung Jeon - wkjeon@kiom.re.kr; Jae Hwan Nam - jhnam@catholic.ac.kr; Young Ran Ju - 38021474@hanmail.net; Young Bong Kim* - kimera@konkuk.ac.kr

* Corresponding author

Published: 30 July 2009

Virology Journal 2009, 6:1 I5 doi:10.1 I86/1743-422X-6-II5

This article is available from: http://www.virologyj.com/content/6/I/II5

(C) 2009 Lee et al; licensee BioMed Central Ltd.

This is an Open Access article distributed under the terms of the Creative Commons Attribution License (http://creativecommons.org/licenses/by/2.0), which permits unrestricted use, distribution, and reproduction in any medium, provided the original work is properly cited.
Received: 20 April 2009

Accepted: 30 July 2009

\begin{abstract}
As noted in other flaviviruses, the envelope (E) protein of Japanese encephalitis virus (JEV) interacts with a cellular receptor and mediates membrane fusion to allow viral entry into target cells, thus eliciting neutralizing antibody response. The formation of the flavivirus $\mathrm{prM} / \mathrm{E}$ complex is followed by the cleavage of precursor membrane (prM) and membrane (M) protein by a cellular signalase. To test the effect of prM in JEV biology, we constucted JEV-MuLV pseudotyped viruses that express the $P r M / E$ protein or $E$ only. The infectivity and titers of JEV pseudotyped viruses were examined in several cell lines. We also analyzed the neutralizing capacities with anti-JEV sera from JEVimmunized mice. Even though prM is crucial for multiple stages of JEV biology, the JEV-pseudotyped viruses produced with $\mathrm{prM} / \mathrm{E}$ or with $\mathrm{E}$ only showed similar infectivity and titers in several cell lines and similar neutralizing sensitivity. These results showed that JEV-MuLV pseudotyped viruses did not require prM for production of infectious pseudotyped viruses.
\end{abstract}

\section{Findings}

Japanese encephalitis virus (JEV) is a serious mosquitoborne flavivirus that causes pandemic infectious disease of major public health importance in Asia. JEV is a member of the genus Flavivirus in the family Flaviviridae, which includes yellow fever virus, Dengue virus, West Nile virus, and St. Louis encephalitis virus $[1,2]$.

The JEV single-stranded RNA genome $(\approx 11 \mathrm{~kb})$ encodes three structural proteins - capsid (C), premembrane
(prM) or membrane $(\mathrm{M})$, and envelope $(\mathrm{E})$ protein - and seven nonstructural (NS1, NS2A, NS2B, NS3, NS4A, NS4B, and NS5) proteins [3-5].

The assembly of JEV in the endoplasmic reticulum is followed by modification of the two envelope proteins $E$ and prM and virion export through the secretory pathway. $\operatorname{PrM}(\approx 26 \mathrm{kDa})$ is a precursor of the membrane-anchored and it cleaved a soluble Pr peptide and virion associated $\mathrm{M}$ protein $(\approx 8 \mathrm{kDa})$ by trans-Golgi resident furin or 
related enzyme [6], resulting in two different forms of virion: the intracellular E- and prM-containing form, and the extracellular E- and M-containing form $[3,7]$.

The E protein plays a major role in virus assembly, adhesion, receptor binding and membrane fusion, hemagglutination inhibition (HI), and induction of neutralizing antibodies (Nabs) [8-10]. Therefore, the E protein is the principal target of neutralization by specific antibodies against JEV infection $[4,11]$. E proteins of JEV expressed in different viral vector systems such as vaccinia virus, sindbis virus, and baculovirus have elicited high levels of neutralizing antibodies against JEV infection and have been tested as second generation JEV vaccines in mice $[7,12$ 14]. From these reports, it is unknown whether prM cleavage affects infectivity, E protein expression, or induction of neutralizing activity. A major function of prM was studied by blocking prM cleavage or by mutation of the conserved glycosylation motif of JEV prM [15]. Even though the direct role of prM during the viral replication was not elucidated [6], it has a crucial function in multiple stages of JEV biology.

We generated pseudotyped viruses containing the $\mathrm{prM} / \mathrm{E}$ or E protein of the current JEV vaccine strains NakayamaNIH (NK) and Beijing-1 (BJ). The DNA fragments encoding the $\mathrm{E}$ and $\mathrm{prM} / \mathrm{E}$ regions were amplified by polymerase chain reaction (PCR) from the cDNA of the NK strain and BJ strain kindly supplied from the Department of Vaccine, KFDA, Korea. PCRs were performed using one of the two forward primers: for prM/E amplification, 5'-AATGAGAATTCGACCATGTGGCTCGCAAGCTTGGC-3'; and for E amplification, 5'-GGTCGCGAATTCTGCAGGTTCAACTGTCTGGGAGTG-3'. The reverse primer for both amplifications was 5'-ACCAATGTGCATGCTTAGCTCGAGAATT

CCATTG-3'. Each primer had an EcoRI restriction site. To generate $\mathrm{pHCMV}-\mathrm{prM} / \mathrm{E}$ and $\mathrm{pHCMV}-\mathrm{E}$, the PCR products of $\mathrm{prM} / \mathrm{E}$ and $\mathrm{E}$ were digested with EcoRI and subsequently cloned into pHCMV-G [16] digested with EcoRI (Figure 1).

Pseudotyped viruses encoding prM/E or E of JEV NK and BJ strain were produced as previously described [17]. Briefly, TELCeB6 cells, a MuLV packaging cell line [18], were transfected with pHCMV-E or pHCMV-prM/E by a calcium phosphate method. After overnight incubation, the culture medium was replaced, and the cells were incubated for two additional days. The supernatants containing pseudotyped viruses were harvested by low speed centrifugation $(1,500 \times g, 5 \mathrm{~min})$ to remove cell debris.

Figure 2 shows the expression of the E proteins from each pseudotyped JEV constructs by western blot analysis using anti-JEV (Nakayama) sera. The envelope genes of the NK and BK strains were expressed well in cell culture supernatants and lysates. Similar amounts of $\mathrm{E}$ proteins were expressed in NK and BJ transfected cells.

The JEV-pseudotyped viruses expressing prM-E and E were properly processed and released into the culture media

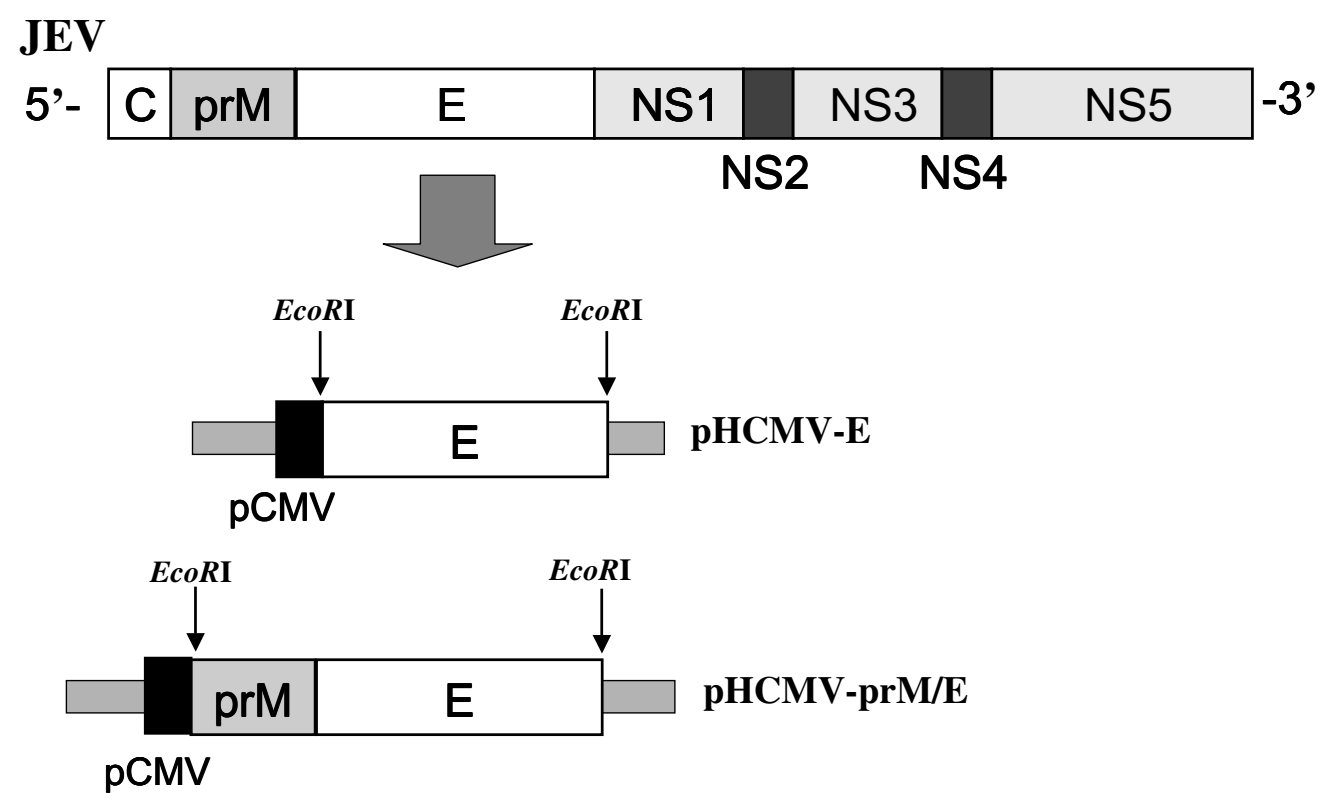

Figure I

Construction of JEV pHCMV-prM/E and pHCMV-E. Four plasmids were produced: $\mathrm{pHCMV}$-prM/E (NK or BJ) and PHCMV-E (NK or BJ). 


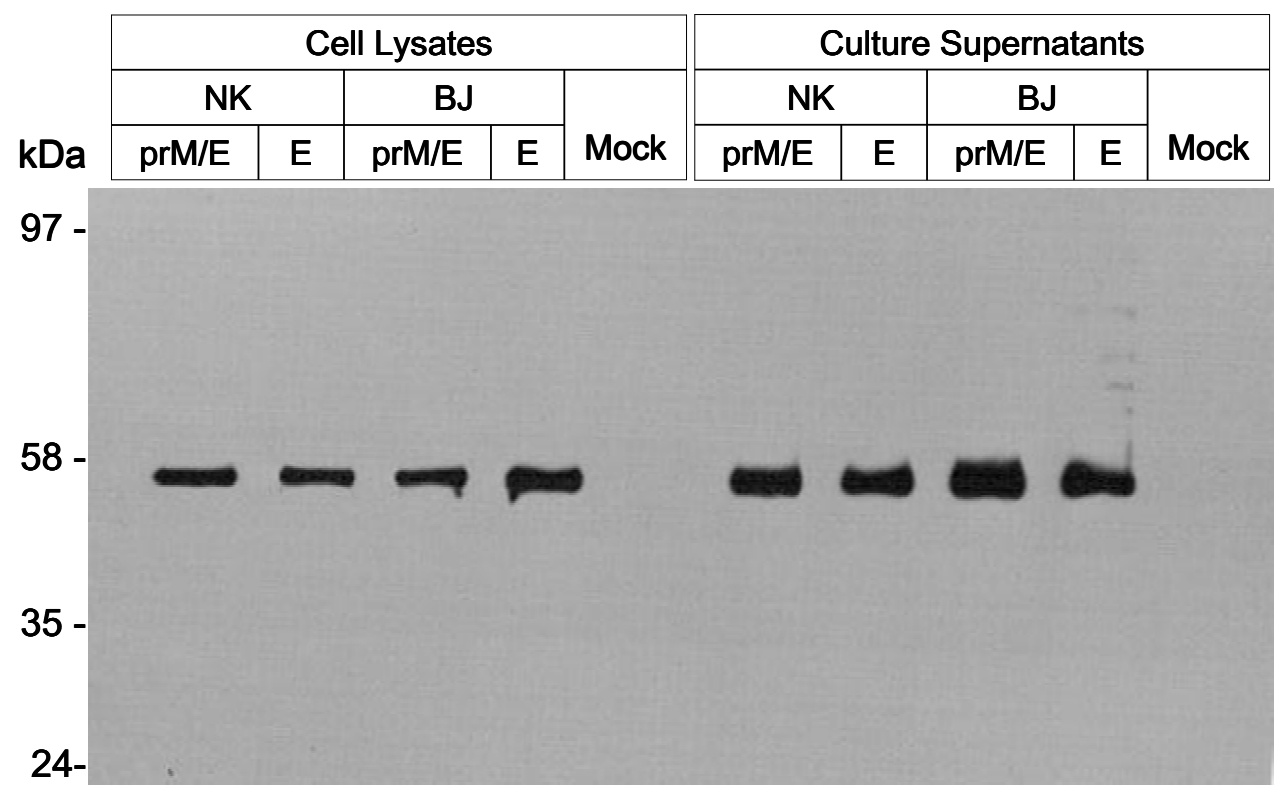

Figure 2

Expression of JEV envelope (E) protein. Cell lysate and culture media of JEV-pseudotyped viruses were subjected to SDSPAGE. JEV-E proteins were detected by western blotting using sera from mice immunized with JEV (Nakayama-NIH strain). The bands show the JEV-E protein $(53 \mathrm{kDa})$ in cell lysates and culture supernatants. Non-transfected TELCeB6 cells were used as a negative control.

with similar levels of expression. However prM-E polyprotein bands were not detected despite many attempts. To check the expression of the prM/Env gene during pseudotyped virus formation, we performed reverse transcription (RT)-PCR. Figure 3 shows the amplified JEV prM/Env
(2062 bp), Env (1501 bp) transcripts in transfected TELCeB6 cells. We assumed that the cleavage of the prM protein is too rapid to detect with prM/E polyprotein and our sera from JEV-immunized mice did not contain the prM antibodies.

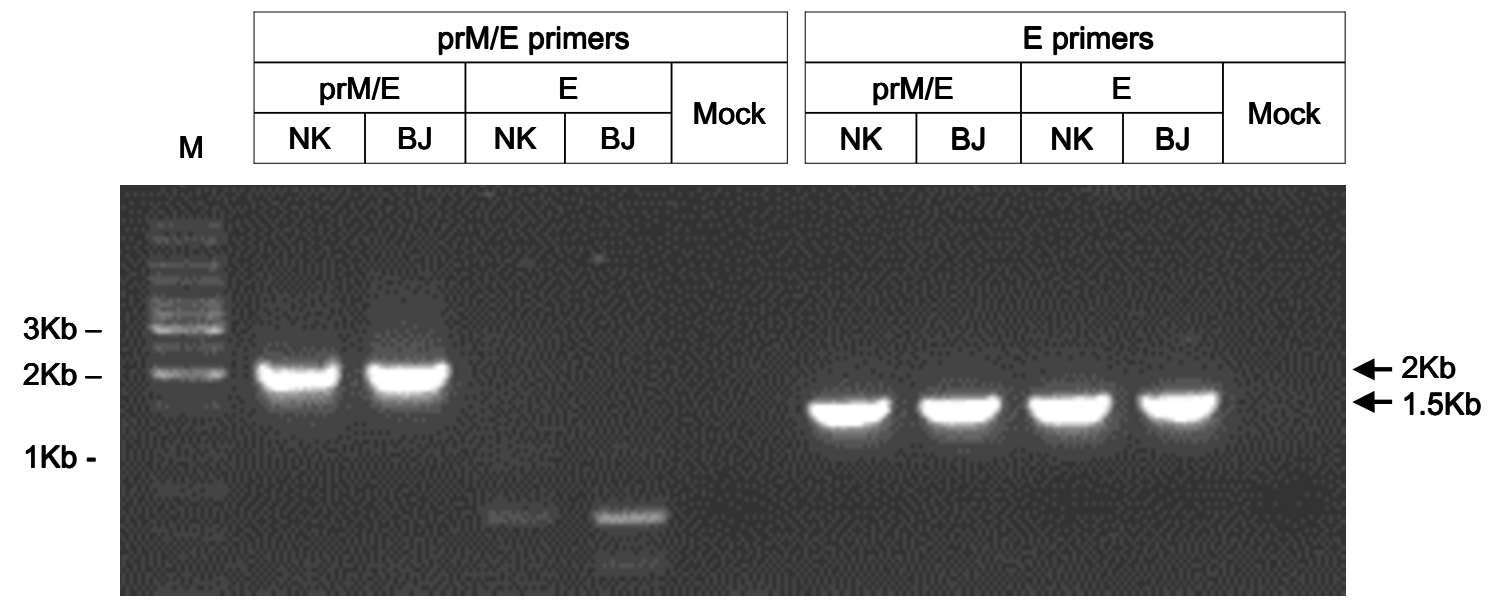

\section{Figure 3}

Expression of JEV prM and Env genes in TELCeB6 cells. TELCeB6 cells were transfected with pHCMV-prM/E and PHCMV-E of each of NK and BJ strains. RT-PCR products of the indicated size were amplified from total RNA samples extracted from TELCeB6 cells. The products correspond to $2 \mathrm{~Kb}$ of prM (amplified by prM/E primer) and I.5 Kb of Env (amplified by $\mathrm{E}$ primer). The molecular marker $(\mathrm{Kb})$ is shown on the left. 
To test the effect of prM on pseudotyped viral infectivity and viral titer, infection tests with the pseudotyped viruses were carried out in in 96-well plates with Vero, PK15, CRFK, NIH3T3, HeLa, 293T, BHK-21, MDCK, and HOS cells. Four kinds of pseudotyped JEVs were added to the host cells and incubated at $37^{\circ} \mathrm{C}$ in a $5 \% \mathrm{CO}_{2}$ incubator for 36 hours. All infections were done in triplicate. After Xgal staining, JEV pseudotyped virus-infected cells appeared blue. This resulted from integration of the MuLV pseudovirus genome encoding $\beta$-galactosidase. These cells were counted as an infectious unit. All JEV pseudotyped viruses could infect PK15, CRFK, NIH3T3, HeLa, 293T, BHK-21, Vero, and MDCK cells, but not HOS cells (Table 1).

The titers of pseudotyped viruses were comparable to the infectivity of JEV in each host cell line. JEV pseudotyped virus with E or prM/E (both NK and BJ strain) could efficiently infect several cell lines, with typical titers between $1.14 \times 10^{2}$ and $1.36 \times 10^{5}$ infectious units (IFU) $/ \mathrm{mL}$. From Table 1, viruses pseudotyped with prM/E exhibited infectivity similar to those pseudotyped with $\mathrm{E}$ only. This showed that the infectivity and titer of JEV pseudotyped virus is not affected by prM deletion.

Neutralizing sensitivity was tested with JEV-immunized immune sera, which was supplied by the Catholic University of Korea, to check the effect of prM on pseudotyped JEV antigens. As previously described [17], neutralization assays were carried out with Vero cells in triplicate. Approximately $100 \mathrm{IFU} / \mathrm{mL}$ of pseudotyped viruses were incubated with 10 -fold diluted sera from mice immunized with JEV for $1 \mathrm{~h}$ at $37^{\circ} \mathrm{C}$, and the mixture was subsequently added to Vero cells. After 2 days of incubation, virus infection was monitored by $\mathrm{X}$-gal staining as described above. The neutralizing sensitivity was expressed as virus reduction by neutralizing antibodies. high neutralization was observed with 1:10 diluted serum. In contrast, no neutralizing activity was detected in the normal mouse serum (reduction was less than 30\%). The neutralization by homologous sera was more complete than that by heterologous sera. However, there was no significant difference between pseudotyped JEV prM/ Env and Env.

In summary, we generated pseudotyped JEVs that express prM/E or E proteins from two JEV vaccine strains NK and BJ. All four JEV pseudotyped viruses efficiently infected several cell lines and were neutralized by sera from JEVimmunized mice. The main purpose of generating JEV pseudotyped virus was to devise a safe and rapid assay system to assess neutralizing antibodies by avoiding the use of infectious, replication-competent JEVs in a Biosafety Level 3 laboratory. The titer of the four JEV pseudotyped viruses was greater than $10^{4} \mathrm{IFU} / \mathrm{ml}$. This confirmed the possibility of mass-producing viruses to conduct neutralization assays with Vero and CRFK cells. Even though a crucial function of prM in assembly and maturation of flaviviruses has been reported, the two types of JEV-MuLV pseudotyped virus that respectively express the E or prM/ E proteins were found to have no significant difference in the level of transcription and the extent of protein expression, infectivity, titer, and neutralization sensitivity.

\section{Competing interests}

The authors declare that they have no competing interests.

\section{Authors' contributions}

HJL, JW, YRJ, YBK participated in the design of the study, HJL, JL, SHK performed the experiments, KIM and JHN provided key reagents, and HJL and YBK edited and approved the final manuscript.

Figure 4 shows the reduction of pseudotyped JEVs by neutralization with homologous and heterologous sera. A

Table I: Infectivity and titer of JEV pseudotyped viruses in host cells

Infectious units/ml (IFU/ml)

\begin{tabular}{|c|c|c|c|c|c|c|c|c|}
\hline \multirow[b]{2}{*}{ JEV pseudotyed virus } & \multicolumn{8}{|c|}{ Host cell } \\
\hline & Vero & BHK-2I & HeLa & CRFK & PKI5 & $293 \mathrm{~T}$ & MDBK & $\mathrm{HOS}$ \\
\hline NK prM/E & $4.09 * 10^{4}$ & $7.46 * 10^{3}$ & $4.08 * 10^{3}$ & $9.74 * 10^{4}$ & $1.33 * 10^{3}$ & $1.14 * 10^{2}$ & $2.08 * 10^{2}$ & 0 \\
\hline NKE & $4.25 * 10^{4}$ & $7.58 * 10^{3}$ & $4.12 * 10^{3}$ & $1.20 * 10^{5}$ & $1.09 * 10^{3}$ & $1.32 * 10^{2}$ & $2.11 * 10^{2}$ & 0 \\
\hline BJ prM/E & $4.12 * 10^{4}$ & $7.76 * 10^{3}$ & $4.35 * 10^{3}$ & $1.02 * 10^{5}$ & $1.82 * 10^{3}$ & $2.04 * 10^{2}$ & $2.08 * 10^{2}$ & 0 \\
\hline BJ $E$ & $4.83 * 10^{4}$ & $7.91 * 10^{3}$ & $4.29 * 10^{3}$ & $1.36 * 10^{5}$ & $2.90 * 10^{3}$ & $2.05 * 10^{2}$ & $2.23 * 10^{2}$ & 0 \\
\hline
\end{tabular}




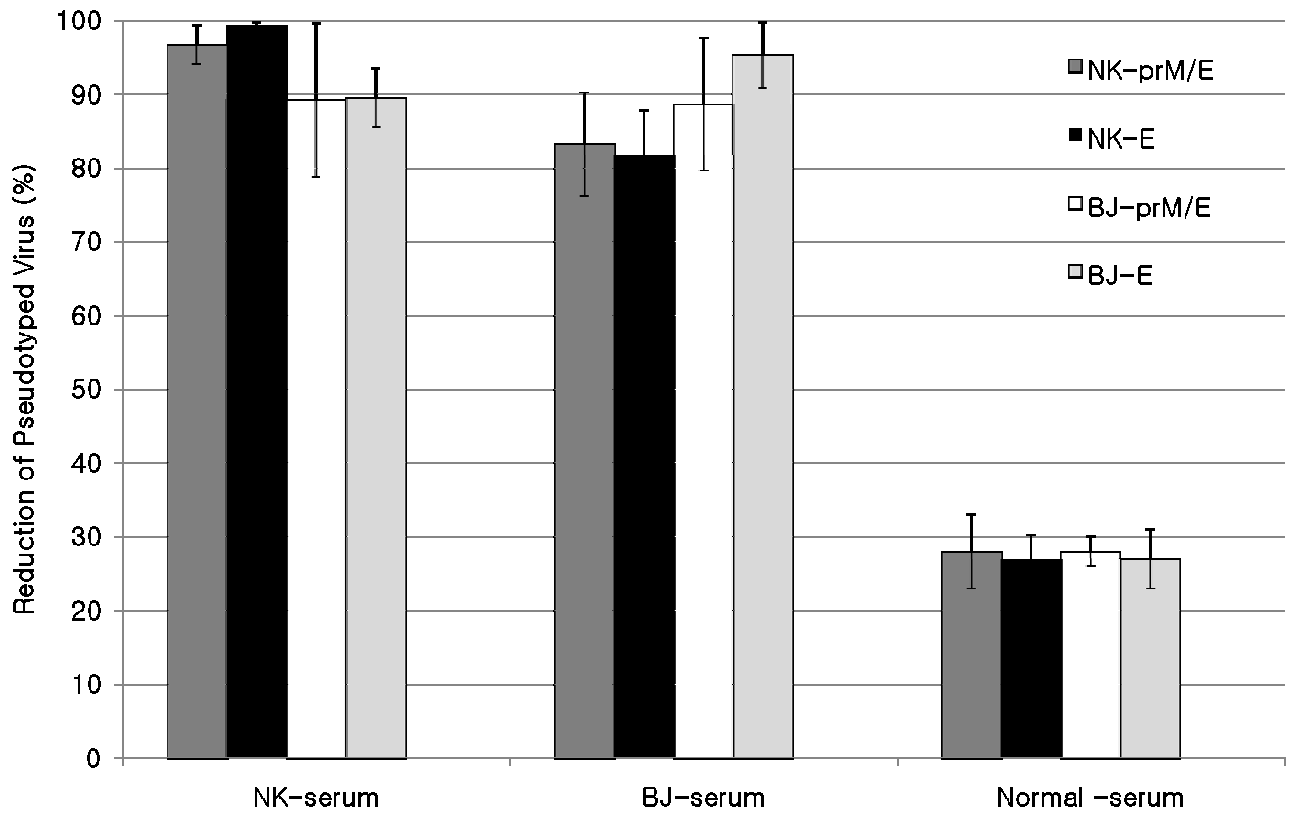

Figure 4

Neutralizing assay with JEV pseudotyped viruses. Four different JEV-pseudotyped viruses (NK-prM/E, dark grey; NK-E, black; BJ-prM/E, white; BJ-E, light grey) were incubated with sera from mice immunized with JEV-NK strain or JEV-BJ strain. Neutralizations were determined with I:I0 diluted serum.

\section{Acknowledgements}

This work was supported by a grant (20070501034009) from BioGreen 21 Program, Rural Development Administration and a Agricultural R\&D Promotion Center, Ministry for Agriculture, Forestry and Fisheries, (60800I5), and a grant [K09040] from the Korea Institute of Oriental Medicine, Republic of Korea.

\section{References}

I. Kuno G, Chang GJ, Tsuchiya KR, Karabatsos N, Cropp CB: Phylogeny of the genus Flavivirus. J Virol 1998, 72:73-83.

2. Venugopal K, Gould EA: Towards a new generation of flavivirus vaccines. Vaccine 1994, I 2:966-975.

3. Yasuda A, Kimura-Kuroda J, Ogimoto M, Miyamoto M, Sata T, Sato T, Takamura C, Kurata T, Kojima A, Yasui K: Induction of protective immunity in animals vaccinated with recombinant vaccinia viruses that express PreM and E glycoproteins of Japanese encephalitis virus. J Virol 1990, 64:2788-2795.

4. Kaur R, Vrati S: Development of a recombinant vaccine against Japanese encephalitis. J Neurovirol 2003, 9:42I-43I.

5. Wu SC, Lian WC, Hsu LC, Liau MY: Japanese encephalitis virus antigenic variants with characteristic differences in neutralization resistance and mouse virulence. Virus Res 1997, 51:173-18I.

6. Keelapang P, Sriburi R, Supasa S, Panyadee N, Songiaeng A, Jairungsri A, Puttikhunt C, Kasinrerk W, Malasit P, Sittisombut N: Alterations of pr-M cleavage and virus export in pr-M junction chimeric dengue viruses. J Virol 2004, 78:2367-238I.

7. Konishi E, Fujii A, Mason PW: Generation and characterization of a mammalian cell line continuously expressing Japanese encephalitis virus subviral particles. J Virol 200I, 75:2204-22I 2.

8. Chen HW, Pan CH, Liau MY, Jou R, Tsai CJ, Wu HJ, Lin YL, Tao MH: Screening of protective antigens of Japanese encephalitis virus by DNA immunization: a comparative study with conventional viral vaccines. J Virol 1999, 73:10137-10145.

9. Kurane I: Immune responses to Japanese encephalitis virus. Curr Top Microbiol Immunol 2002, 267:91-103.
10. Mason PW, Dalrymple JM, Gentry MK, McCown JM, Hoke CH, Burke DS, Fournier MJ, Mason TL: Molecular characterization of a neutralizing domain of the Japanese encephalitis virus structural glycoprotein. J Gen Virol I989, 70(Pt 8):2037-2049.

II. Kojima A, Yasuda A, Asanuma H, Ishikawa T, Takamizawa A, Yasui K, Kurata T: Stable high-producer cell clone expressing virus-like particles of the Japanese encephalitis virus e protein for a second-generation subunit vaccine. J Virol 2003, 77:8745-8755.

12. Wu HH, Chen CT, Lin YL, Lee ST: Sub-fragments of the envelope gene are highly protective against the Japanese encephalitis virus lethal infection in DNA priming - protein boosting immunization strategies. Vaccine 2004, 22:793-800.

13. Zhao Z, Wakita T, Yasui K: Inoculation of plasmids encoding Japanese encephalitis virus PrM-E proteins with colloidal gold elicits a protective immune response in BALB/c mice. Virol 2003, 77:4248-4260.

14. Konishi E, Pincus S, Paoletti E, Shope RE, Burrage T, Mason PW: Mice immunized with a subviral particle containing the Japanese encephalitis virus prM/M and $E$ proteins are protected from lethal JEV infection. Virology I992, I 88:7|4-720.

15. Kim JM, Yun SI, Song BH, Hahn YS, Lee CH, Oh HW, Lee YM: A single $\mathrm{N}$-linked glycosylation site in the Japanese encephalitis virus prM protein is critical for cell type-specific prM protein biogenesis, virus particle release, and pathogenicity in mice. J Virol 2008, 82:7846-7862.

16. Burns JC, Friedmann T, Driever W, Burrascano M, Yee JK: Vesicular stomatitis virus $\mathbf{G}$ glycoprotein pseudotyped retroviral vectors: concentration to very high titer and efficient gene transfer into mammalian and nonmammalian cells. Proc Nat Acad Sci USA 1993, 90:8033-8037.

17. Kim YB, Lee MK, Han DP, Cho MW: Development of a safe and rapid neutralization assay using murine leukemia virus pseudotyped with HIV type I envelope glycoprotein lacking the cytoplasmic domain. AIDS Res Hum Retroviruses 200I, I7:1715-1724.

18. Schnierle BS, Stitz J, Bosch V, Nocken F, Merget-Millitzer H, Engelstadter M, Kurth R, Groner B, Cichutek K: Pseudotyping of murine leukemia virus with the envelope glycoproteins of 
HIV generates a retroviral vector with specificity of infection for CD4-expressing cells. Proc Natl Acad Sci USA 1997, 94:8640-8645.

Publish with Bio Med Central and every scientist can read your work free of charge

"BioMed Central will be the most significant development for disseminating the results of biomedical research in our lifetime. " Sir Paul Nurse, Cancer Research UK

Your research papers will be:

- available free of charge to the entire biomedical community

- peer reviewed and published immediately upon acceptance

- cited in PubMed and archived on PubMed Central

- yours - you keep the copyright

Submit your manuscript here:

http://www.biomedcentral.com/info/publishing_adv.asp 